\title{
Madridge
}

madridge Journal of Nanotechnology \& Nanoscience

Interconnecting Scientific World

Research Article

Open Access

\section{Preparation and Characterization of the PVA Nanofibers produced by Electrospinning}

\author{
Tariq J Alwan ${ }^{1 \star}$, Ziad Abdulahad Toma ${ }^{1}$, Muhsin A Kudhier ${ }^{1}$ and Kareema M Ziadan ${ }^{2}$ \\ ${ }^{\prime}$ Department of Physics, College of Education, Al-Mustansiriyah University, Baghdad, Iraq \\ ${ }^{2}$ Department of Physics, College of Education, University of Basrah, Basra, Iraq
}

\section{Article Info}

*Corresponding author:
Tariq J Alwan
Department of Physics
College of Education
Al-Mustansiriyah University
Baghdad, Iraq
Tel: 009647705351515
E-mail: tariqjaffer2000@yahoo.com

Received: February 9, 2016

Accepted: March 10, 2016

Published: March 15, 2016

Citation: Alwan TJ, Toma ZA, Kudhier MA, Ziadan KM. Preparation and Characterization of the PVA Nanofibers produced by Electrospinning. Madridge J Nanotechnol Nanosci. 2016; 1(1): 1-3.

doi: $10.18689 / \mathrm{mjnn}-1000101$

Copyright: @ 2016 The Author(s). This work is licensed under a Creative Commons Attribution 4.0 International License, which permits unrestricted use, distribution, and reproduction in any medium, provided the original work is properly cited.

Published by Madridge Publishers

\begin{abstract}
Electrospinning is a simple and quick technique for producing fibers with nanoscale diameters from a wide range of materials. The Polyvinylalcohol PVA Polymer dissolved in the DMF was electrospun to obtain the alignment nanofibers PVA. The nanofibers were obtained using $25 \mathrm{wt} \%$ solution concentration, an applied voltage $10 \mathrm{kV}$, spinning distance $10 \mathrm{~cm}$ and different flow rates of $0.1,0.2$, and $0.3 \mathrm{ml} / \mathrm{hr}$. The properties of alignment nanofibres including morphology, crystallization, functional group and the effect of flow rates on it was studied. The morphology of the electrospun PVA nanofibres is studied using scanning electron microscopy (SEM). Structural characteristics analysis by X-ray diffraction (XRD) that showed the crystalline peaks of the PVA nanofibers. The formation of functional groups of PVA polymer was predicted by the FT-IR spectra
\end{abstract}

Keywords: PVA; Electrospinning; Nanofibers; Flow rate.

Abbreviations: PVA: Polyvinylalcohol; XRD: X-ray diffraction; SEM: Scanning Electron Microscopy

\section{Introduction}

Electrospinning is known as one of the famous methods to produce fibers in nanoscale, from different materials. These nanofibers shows several important characteristics such as a large surface area to the volume ratio, high porosity, and superior mechanical properties [1].

Nanofibers are a new class of material with special characteristics which make them appropriate for a wide range of applications such as filtration, aerospace, capacitors, transistors, drug delivery systems, battery separators, energy storage, fuel cells, and information technology [2].

In the electrospinning process, a high electric field is applied to polymer solution which is held in a plastic syringe with a capillary needle. An electric force caused by mutual charge repulsion acts opposite to surface tension. When the electric field is high enough, the polymer solution on the tip of the capillary needle elongates and forms a cone, known as Taylor cone. A critical value of the electric field exists for which the repulsive electrical force overcomes the surface tension. The polymer solution could generate a charge jet from the tip of the Taylor cone when a critical value is reached. As the jet accelerates in the electric field, radial charge repulsion results in the splitting of the primary jet into multiple filaments [3]. The diameter and size of nanofibres that produce by electrospinning method is affected by many factors such as, molecular weight of the polymer, solution properties, electric potential, flow rate, distance between the capillary and collection screen, and needle gauge [4]. 
Many types of polymers have successfully been electrospun into micr-nanofiber, like polyolefins, polyamides, polyesters, polyurethanes, polypeptides, polysaccharides, and polyvinylalcohol (PVA).

The aim of this work, have fabricated orientation PVA nanofibers by using electrospinning process with rotating collector, then study the effect of flow rates on the nanofibers diameters, morphology, alignment and structure of PVA nanofibers.

\section{Experimental}

Pure Polyvinylalcohol PVA polymer supplied by the ICI company $\left(\mathrm{M}_{\mathrm{w}}=200.000\right)$, was dissolved in DMF at $25 \mathrm{wt} \%$ concentration, the solution was stirred using a magnetic stirrer for $3 \mathrm{~h}$ until the polymer completely dissolved.

$2 \mathrm{ml}$ of the solution was placed in a syringe, the syringe was connected to a metal needle an adjustable DC power supply held at the tip of the needle as an anode and rotating an aluminum cylinder collector as a cathode. The processing conditions of the different flow rates of $0.1,0.2$, and $0.3 \mathrm{ml} / \mathrm{h}$ were as below; the electrospun voltage is $10 \mathrm{kV}$, the distance between the needle and collector is $10 \mathrm{~cm}$, and the needle diameter was $23 \mathrm{G}$. After electrospinning, the collected fibers samples were kept in an oven at room temperature for two hours to dry.

The collected electrospun nanofibers produced in the various experiments were characterized by scanning electron microscopy SEM to assess the fiber diameter, morphology, and alignment, SEM analysis was performed on a Hitachi S-4160 SEM. The structural characteristics of PVA nanofibers films were determined by $X$-ray diffraction. The measurement has been done by using Philips $X$ - ray diffractometer that having the following features: source $\mathrm{Cu}$, current was $30 \mathrm{~mA}$, voltage was $40 \mathrm{kV}$, and the wavelength $(I=1.5405 \mathrm{Ao})$. The characterization bonds between the functional groups were measured by Fourier Transform Infrared FT-IR spectra (Shimadzu FTIR-8400S), all spectra was recorded between 4000 and $400 \mathrm{~cm}^{-1}$.

\section{Results and Discussion}

The morphology, nanofibers diameters and alignment of produced PVA nanofibers were examined using SEM. Figure (1) showed the SEM images of PVA nanofibers with different flow rates $0.1,0.2$, and $0.3 \mathrm{ml} / \mathrm{h}$. The electrospinning of nanofibers from PVA soluble in DMF at concentration lower $25 \mathrm{wt} \%$ was difficult, to formation fibers, as the viscosity and surface tension of the solution were not high enough to maintain a stable drop at the end of the capillary tip.

From Figure 1 it was obviously observed that the PVA nanofibers exhibited uniaxial aligned nanofibers were obtained at all flow rates $0.1,0.2$, and $0.3 \mathrm{ml} / \mathrm{h}$, under the same other conditions. However, it can be also seen from these images that there are fibers which are free from defects such as beads, relatively smooth and a generally uniform thickness along the fiber especially at low flow rates.
The increase of flow rate leads to decrease the number of nanofibers per unit area, and from another hand, the $0.1 \mathrm{ml} / \mathrm{h}$ flow rate appears to have the best alignment and the lower average diameters, the average diameters were increasing with increase the flow rate, but at all flow rates the diameters were under $100 \mathrm{~nm}$.

Figure 2 shows X-ray diffraction (XRD) patterns of the PVA nanofibers in different flow rates. The diffraction pattern of PVA showed only one peak characteristic of crystalline PVA at $2 q=18.7$ and this agreement with Sharma $R$, et al. 2014, and Nguyen Thuy $2010[5,6]$, the characteristic peaks of PVA naoafibers were appear in all samples that preparation in different flow rates.
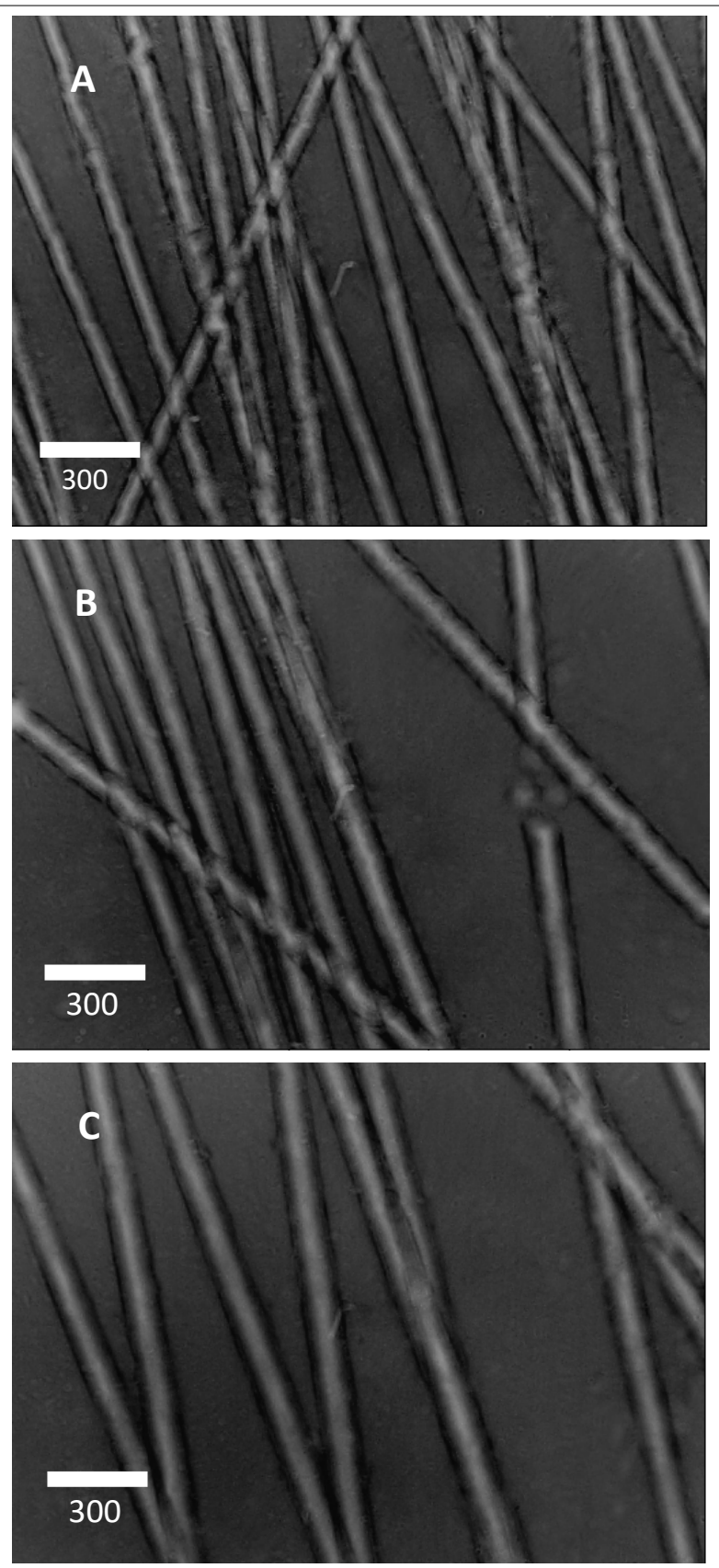

Figure 1: SEM images for electrospun PVA nanofibers prepared in different flow rates: (A) $0.1 \mathrm{ml} / \mathrm{h} \mathrm{(B)} 0.1 \mathrm{ml} / \mathrm{h}$ (C) $0.3 \mathrm{ml} / \mathrm{h}$

The average crystallite size (D) of the semicrystalline material can be calculated from the XRD spectrum by means of Full Width at Half Maximum (FWHM) method (Scherrer relation) [7]. 


$$
D=\frac{A \lambda}{\Delta \theta \cos \theta}
$$

Where $\Delta \theta$ is the full - width at half maximum of the XRD peak appearing at the diffraction angle $\theta$, A Scherrer constant, usually assume $A=1$, and I the wavelength of $X$-ray.

The results of average crystallite size are $(101.5 \mathrm{~nm}, 95.8$ $\mathrm{nm}, 91.3 \mathrm{~nm}$ for flow rates $0.1,0.2$, and $0.3 \mathrm{ml} / \mathrm{h}$ respectively, the sample prepared at flow rate $0.3 \mathrm{ml} / \mathrm{h}$ showed the lower crystallite size $(91.3 \mathrm{~nm})$ and its value increases with decrease the flow rate, The increase in crystallite size indicates uniformity, which may be due to improvement in the structure during the formation of nanofiber, and the electrospinning process [8-10].

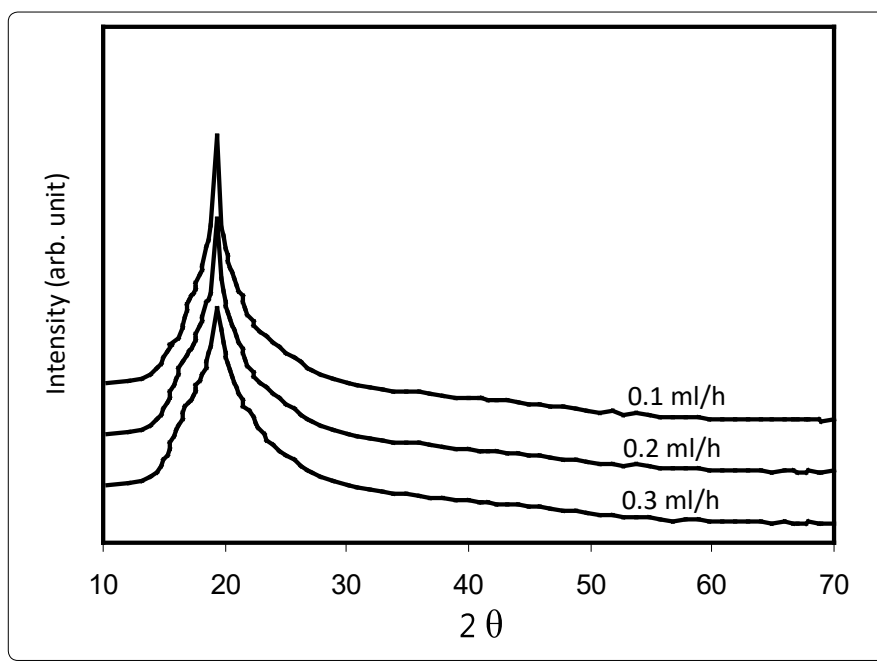

Figure 2: XRD spectra of PVA nanofibers prepared in different flow rates.

Figure 3 shows the FTIR spectra of PVA nanofibers, the absorption peaks of PVA nanofibers at about $3239 \mathrm{~cm}^{-1}$ refer to $\left(-\mathrm{OH}\right.$ stretching), The bands corresponding to the $\left(-\mathrm{CH}_{2}{ }^{-}\right)$ asymmetric and the symmetric stretching at $2900 \mathrm{~cm}^{-1}$. The band at $1340 \mathrm{~cm}^{-1}$ can be attributed to $\mathrm{O}-\mathrm{H}$ and $\mathrm{C}-\mathrm{H}$ bonding. The band at $958 \mathrm{~cm}^{-1}$ result from an angular deformation outside the plan of an $\mathrm{O}-\mathrm{H}$ bond [11], from the Figure 3 notice that the spectrum of all samples are similar, observed a small change in intensity of the bands in the different flow rate. Nevertheless, there are no additional vibrational bands. Therefore the effect of flow rates on the PVA nanofibers does not effect on the bonds structure and this agreement with Sujith, et al. [12]

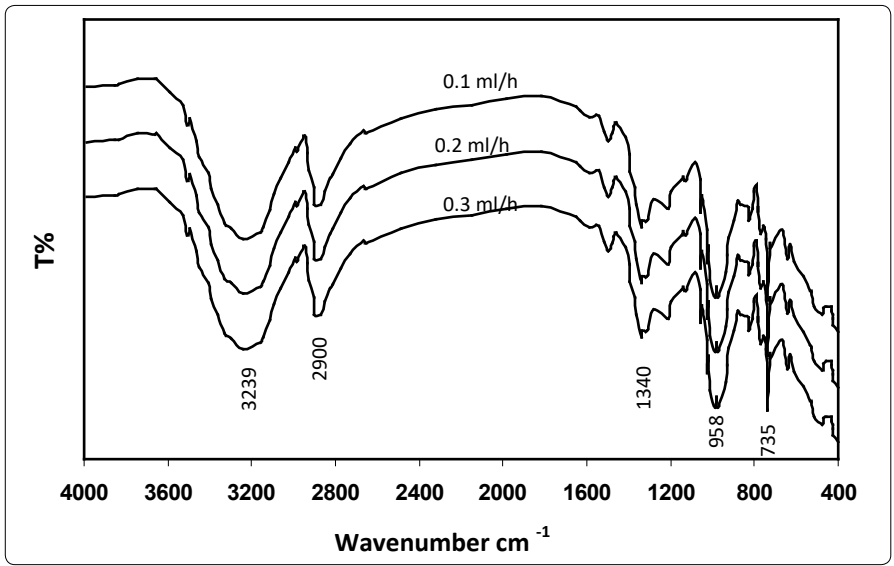

Figure 3: FT-IR spectra of PVA nanofibers prepared in different flow rates.

\section{Conclusions}

PVA nanofibers have been successfully produced using an electrospinning technique. The effect of flow rates on the morphology, nonfibers diameters, crystallinity, and functional groups of electrospun PVA nanofibers were investigated. It was found that the increase of flow rate was increasing the nonfibers diameters, and decreases the fiber crystallinity state. The flow rate was not effect on the bonds structure of the PVA nanofibers.

\section{References}

1. Zargham S, Bazgir S, Tavakoli A, Rashidi AS, Damerchely R. The effect of flow rate on morphology and deposition area of electrospun nylon. Nanofiber Journal of Engineered Fibers and Fabrics. 2012; 7(4): 42-49.

2. Khan SN. Electrospinning polymer nanofibers - electrical and optical characterization. The College of Arts and Science of Ohio University. 2007.

3. Qian YF, Su Y, Li XQ, Wang HS, Long C. Electrospinning of polymethyl methacrylate nanofibres in different solvents. Iranian Polymer Journal. 2010; 19(2): 123-129.

4. Ramakrishna S, Fujihara K, Teo W, Lim T, Ma Z. An introduction to electrospinning and nanofibers. World Scientific Publishing Co. Pte. Ltd. 2005.

5. Sharma R, Singh N, Gupta A, Tiwari S, Tiwari SK, Dhakate SR. Electrospun chitosan-polyvinyl alcohol composite nanofibers loaded with cerium for efficient removal of arsenic from contaminated water. J. Mater. Chem. A. 2014; 39: 16669-16677. Doi: 10.1039/C4TA02363C

6. Linh NTB, Min YK, Song HY, Lee BT. Fabrication of polyvinyl alcohol/ gelatin nanofiber composites and evaluation of their material properties. Journal of Biomedical Materials Research B: Applied Biomaterials. 2010; 95(1): 184-191. Doi: 10.1002/jbm.b.31701

7. Cullity BD, Stock SR. Elements of $X$ - ray Diffraction. Prentice-Hall in the United States of America. $3^{\text {th }}$ ed. USA, 2001.

8. Ero-Phillips $O$, Jenkins $M$, Stamboulis A. Tailoring crystallinity of electrospun plla fibres by control of electrospinning parameters. Polymers. 2012; 4: 1331-1348. Doi: 10.3390/polym4031331

9. Solyom J. Fundamentals of the physics of solids. Springer-Verlag Berlin Heidelberg. 2007; 1: 697 Doi: 10.1007/978-3-540-72600-5

10. Zhao $S, W u X$, Wang $L$, Huang $Y$. Electrospinning of ethyl-cyanoethyl cellulose/tetrahydrofuran solutions Sci. J. Appl. Polym. 2004; 91: 242246. DOI: $10.1002 / a p p .13196$

11. Labidi NS, Djebaili A. Studies of the mechanism of polyvinyl alcohol adsorption on the calcite/water interface in the presence of sodium oleate. Journal of Minerals \& Materials Characterization \& Engineering, 2008; 7(2): 147-161. Doi: 10.4236/jmmce.2008.72012

12. Sujith $K$, Asha AM, Anjali $P$, et al. Fabrication of highly porous conducting PANI-C composite fiber mats via electrospinning. Materials Letters. 2012; 67(1): 376-378. 